b) If there is suspicion of eyeball or eyelid laceration, a plastic shell (or paper cup secured with tape) should be placed to prevent rubbing.

c) Immediate referral to a specialized facility.

\section{CONCLUSION}

The age at which the trauma incidence was higher was the 6-11-year-old age group; male gender was most commonly affected; and most patients suffered blunt force trauma. In this series, 15 patients who underwent traumatic cataract surgery and completed 1 year of followup achieved a $20 / 70$ or better VA.

\section{REFERENCES}

1. Al-Mahdi HS, Bener A, Hashim SP. Clinical pattern of pediatric ocular trauma in fast developing country. Int Emerg Nurs 2011;19(4):186-91.

2. Abbott J, Shah P. The epidemiology and etiology of pediatric ocular trauma. Surv Ophthalmol 2013;58(5):476-85.

3. Gogate P, Sahasrabudhe M, Shah M, et al. Causes, epidemiology, and long-term outcome of traumatic catarcts in children in rural India. Indian J Ophthalmol 2012; 60(5):481-6.

4. Neely D, Wilson E, Plager D, et al. Cataracts in Childhood. Orbis International. 2016. [Accessed on: March 7 $7^{\text {th }}$ 2017]. Available at: https://d1dk84hmsdb5u9.cloudfront. net / 991974c8-8e3f-431f-82ec-21b0fb7c92dc/Resources /
Cataracts $\% 20$ in $\% 20$ Children $\% 20$ Manual.pdf.

5. Shah M, Shah S, Applewar A, et al. Ocular Trauma Score as a predictor of final visual outcomes in traumatic cataract cases in pediatric patients. J Cataract Refract Surg 2012; 38(6):959-65.

6. Reddy A, Ray R, Yen K. Surgical intervention for traumatic cataracts in children: Epidemiology, complications, and outcomes. J AAPOS 2009;13(2):170-4.

7. Xu Y, Huang $Y$, Xie L. Pediatric traumatic cataract and surgery outcomes in eastern China: a hospital-based study. Int J Ophthalmol 2013;6(2):160-4.

8. Quezada-del Cid N, Zimmermann-Paiz M, OrdoñezRivas A. Características clínicas y epidemiológicas del trauma ocular en menores de 14 años. Arch Argent Pediatr 2015;113(5):e260-63.

9. Pons-Castro L, Arias-Díaz A, Naranjo Fernández R, et al. Resultadosdel tratamientoquirúrgicodelacatarata traumática en edad pediátrica. Rev Cuba Oftalmol 2010;23(2)209-218.

10. Razo-Blanco-Hernández DM, Pérez-Bastida XI, SánchezNava MF, et al. Estimación del daño por trauma ocular en pediatría sin la evaluación de la agudeza visual. Bol Med Hosp Infant Mex 2011;68(5):337-41.

11. Rumelt S, Rehany U. The influence of surgery and intraocular lens implantation timing on visual outcome in traumatic cataract. Graefes Arch Clin Exp Ophthalmol 2010;248(9):1293-7.

12. Shah M, Shah S, Upadhyay P, Agrawal R. Controversies in traumatic cataract classification and management: a review. Can J Ophthalmol 2013;48(4):251-8.

13. Shah M, Shah S, Shikhangi K, et al. Factors Affecting Visual Outcome Following Surgical Treatment of Cataracts in Children. Open J Ophthalmol 2012;2(4):131-9.

\title{
Prevalence of cow's milk protein allergy among children in a university community hospital
}

\author{
Romina Mehaudy, M.D. ${ }^{a, b}$, Claudio A.S. Parisi, M.D. ${ }^{c, b, f,}$, Natalia Petriz, M.D. ${ }^{c, b}$, Alfredo Eymann, M.D. ${ }^{d}$,
} María B. Jaureguie, B.S. ${ }^{b}$ and Marina Orsi, M.D. ${ }^{a, b}$

a. Department of Pediatric Gastroenterology

b. Food Allergies Interdisciplinary Service.

c. Division of Pediatric Allergy, Department of Clinical Pediatrics.

d. Department of Clinical Pediatrics.

e. Department of Nutrition.

Hospital Italiano de Buenos Aires.

f. Food Allergy Task Force of International Life Sciences Institute (ILSI), Argentina.

E-mail addres:

Claudio A.S. Parisi, M.D.: claudio.parisi@hospitalitaliano.org.ar

Funding: None.

Conflict of interest: None.

Received: 8-14-2017

Accepted: 10-26-2017

\begin{abstract}
Cow's milk protein allergy (CMPA) is the most common food allergy in pediatrics. In Argentina, the prevalence of this disease has been evaluated in a few trials.

Objectives. To estimate the prevalence of CMPA and describe its variation throughout a period of 11 years.

Population and methods. A retrospective cohort study was carried out in live newborn infants enrolled in a health care program of a university community hospital.

Results. Onehundred and sixteen cases of children with CMPA were identified. Cumulative prevalence was $0.8 \%$ (95\% confidence interval [CI]: $0.65-0.95$ ). A percent increase of $0.4 \%$ in 2004 to $1.2 \%$ in 2014 was observed in the number of cases per year. Conclusion. In 2014, CMPA prevalence was $1.2 \%$, i.e. three times that of 2004.

Key words: food allergy, cow milk, child, prevalence.
\end{abstract}


To cite: Mehaudy R, Parisi CAS, Petriz N, et al. Prevalence of cow's milk protein allergy among children in a university community hospital. Arch Argent Pediatr 2018;116(3):219-223.

\section{INTRODUCTION}

Cow's milk protein allergy (CMPA) is the most common food allergy in pediatrics, with a prevalence ranging between $1.8 \%$ and $7.5 \%$ in the first year of life. ${ }^{1}$

It is defined as a reproducible adverse immune reaction induced by cow's milk protein. It may be classified into three categories: a) immunoglobulin E (IgE)-mediated, with an immediate onset of symptoms after the intake; b) non-IgE-mediated, with a late onset of symptoms, or c) with mixed symptoms. ${ }^{1,2}$

Besides, due to the food allergy symptoms perceived and reported by patients, this illness has been diagnosed up to 10 times in excess. ${ }^{3}$ This situation may lead to avoidant eating behaviors, unbalanced diets and an impact on the patients and their families' quality of life. ${ }^{4,5}$

The prevalence of food allergy may vary among different contexts according to cultural characteristics, the preparation, and the local factors affecting the exposure to this type of food. ${ }^{2}$

In Argentina, the prevalence of food allergy has been evaluated in a few trials. ${ }^{6}$ This information is relevant in order to improve education, preventive strategies and the design of policies about eating.

\section{OBJECTIVE}

To estimate the prevalence of CMPA among children in a university community hospital from 2004 to 2014, and to describe its variation throughout that period of time.

\section{PATIENTS AND METHODS}

A retrospective, cohort study was carried out from January 1 1, 2004 to December 31 $1^{\text {st }}, 2014$.

The population was made up of all live newborn infants in Hospital Italiano de Buenos Aires (HIBA), and the sample consisted of all the live newborn infants who were enrolled in Hospital Italiano's Medical Program (PMHI).

The PMHI is a health organization which provides medical services to more than 150000 people. It comprises two main hospitals and 24 centers featuring medical offices, and it delivers an average of 95 births per month in the Autonomous City of Buenos Aires and Greater Buenos Aires.
Electronic medical records of all births occurred during the study period were reviewed. The different cases were identified through the following media: a) databases of the Division of Allergy and the Department of Pediatric Gastroenterology, and b) electronic register of patients with International Classification of Primary Care (ICPC) code, and code T 78.1 of the International Disease Classification 10 (IDC 10).

Each medical record with a potential CMPA diagnosis was confirmed by allergy and gastroenterology experts in accordance with the World Allergy Organization guidelines for the Diagnosis and Rationale for Action against Cow's Milk Allergy (DRACMA). ${ }^{3}$

CMPA diagnosis was confirmed if the child met at least one of the following criteria: ${ }^{2}$

1. Patients with symptoms of immediate hypersensitivity and positive specific $\operatorname{IgE}$ confirmation through an immediate-reading skin test or an enzyme-linked immunosorbent assay (ELISA) with positive result for cow's milk proteins, or positive food challenge test in those cases where there was clinical suspicion but negative test results.

2. Patients with late symptoms and negative specific IgE, improvement secondary to diet, and return of symptoms after open food challenge.

The following outcome measures were defined: sex; type of delivery (vaginal, C-section); age at the time of diagnosis; baseline symptoms: a) non-specific gastrointestinal symptoms, such as diarrhea, nausea, vomiting, abdominal cramps or bloody stools (non-IgE-mediated, appearing one hour to several days after exposure), b) urticaria, rhinitis, bronchospasm, anaphylaxis (IgEmediated, appearing within an hour of exposure), and c) atopic dermatitis (mixed mechanism); feeding type at the onset of symptoms: exclusive breastfeeding, introduction of modified milk, introduction of dairy products.

The study was approved by the Research Protocol Evaluation Committee of HIBA. The prevalence of CMPA among children was calculated as the detected number of children with CMPA divided by the number of annual births. Categorical outcome measures were described as percentages, and continuous outcome measures were expressed as mean and standard deviation (SD). The STATA 12, USA, statistical software was used. 


\section{RESULTS}

Between January 2004 and December 2014, 14710 births were recorded and 116 cases of children with CMPA diagnosed at birth or within their first year of life were identified. The prevalence during the study period was $0.8 \%$ (95\% confidence interval [CI]: 0.65-0.95). The diagnosis of CMPA increased with time: from
$0.4 \%$ in 2004 to $1.2 \%$ in 2014 (Figure 1).

Patients with CMPA showed the following clinical characteristics: $55.2 \%$ were girls, average age at diagnosis was 3.6 months (standard deviation [SD] of 2.1; range: 1-11 months). Children born through C-section accounted for $55.8 \%$ of cases (Table 1 ).

The most frequent symptoms at baseline

FIGURE 1. Prevalence of cow's milk protein allergy between 2007 and 2014

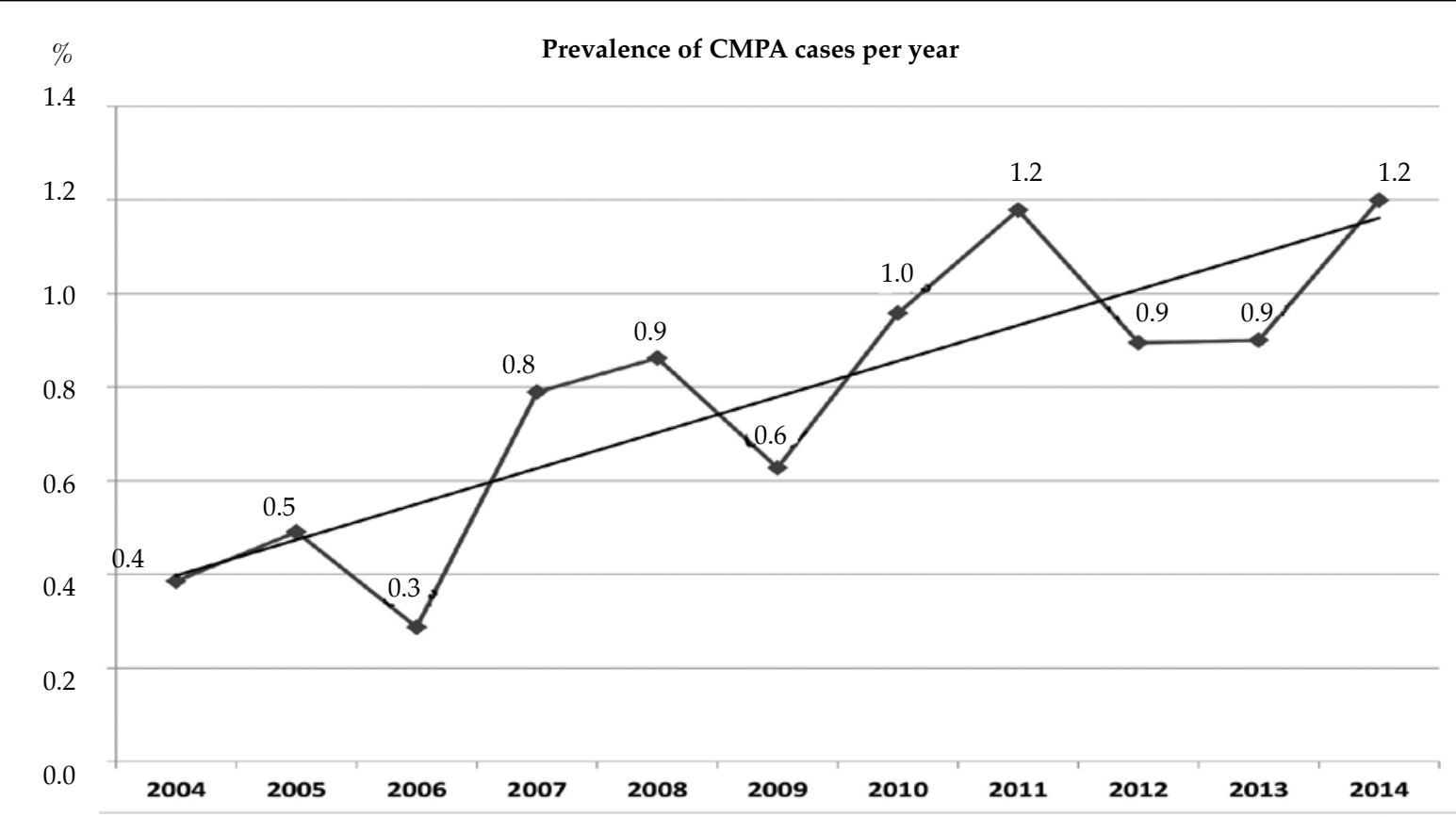

CMPA: cow's milk protein allergy.

Year

TABLE 1. Clinical characteristics of children with cow's milk protein allergy

\begin{tabular}{lll}
\hline & & $\mathbf{N}=\mathbf{1 1 6}$ \\
\hline${ }^{*}$ Sex & Male & $52(44.8)$ \\
& Female & $64(55.2)$ \\
** Age in months & & $3.6(2.1)$ \\
* Baseline symptoms & Bloody stools & $48(41.4)$ \\
& Non-specific gastrointestinal symptoms & $20(17.2)$ \\
& IgE-mediated symptoms & $32(27.6)$ \\
$*$ Feeding type at the onset of symptoms & Mixed symptoms & $16(13.8)$ \\
& Exclusive breastfeeding & $18(15.6)$ \\
$*$ Type of delivery & Introduction of modified milk & $79(68.7)$ \\
& Introduction of dairy products & $18(15.6)$ \\
\hline
\end{tabular}

* Number of cases and percentage.

* Mean and standard deviation. 
were bloody stools (41.4\%), and IgE-mediated symptoms represented $27.6 \%$. In $68.7 \%$ of the cases, symptoms started when modified milk was introduced (Table 1).

\section{DISCUSSION}

CMPA prevalence was of $1.2 \%$ in 2014 , with an increase of $0.4 \%$ to $1.2 \%$ along the 11 years of the study, which was consistent with that mentioned in international reports. ${ }^{7-9}$

CMPA usually develops during the first year of life, mainly because cow milk is frequently the first food protein to which children are exposed. ${ }^{10}$ Accordingly, our study describes average age at diagnosis is 3.6 months, and in most cases (68.7\%) it coincides with the introduction of modified milk to the infant's diet.

A meta-analysis of European studies ${ }^{11}$ revealed that most published studies were based on selfreported data; only few studies were able to confirm suspicious cases by means of a complete clinical assessment and oral challenges.

The prevalence of CMPA is affected by genetic and environmental differences, and might vary in different geographic areas. ${ }^{2}$ Yet, the prevalence result in our study was similar to that of other European studies. Eggesbo et al. studied a population of 2.5 year-old Norwegian children, and found a prevalence of $1.2 \%$ in 2001. Most of these patients showed non-IgEmediated mechanisms. ${ }^{7}$ Venter et al. obtained identical results in a population of 2 year-old English children assessed by means of skin tests and food challenge tests. ${ }^{8}$ The same occurred in a French study published by Rance et al., who described a prevalence of $1.1 \%$ of CMPA within a population of children between 2 and 14 years old in 2005. ${ }^{9}$ The results are similar, and the populations present different genetic and environmental characteristics, but these studies are not comparable due to a significant heterogeneity emerging from the different methodological and diagnostic criteria applied.

By means of a meta-regression (statistical method used in meta-analysis) of 20 surveys performed between 1988 and 2011 on a population of 400000 children in the United States, an increase of $1.2 \%$ per decade was estimated in the general prevalence of food allergies. ${ }^{12}$ Another fact that can be used to estimate the increase of this prevalence is the growing number of hospitalizations due to anaphylaxis caused by food. ${ }^{13}$ Prevalence was found to have triplicated along the 11 years of our study.
This increase in prevalence cannot be explained by the genetic diversity; therefore, it might be the result of environmental factors associated to modern lifestyle. Among the investigated factors, we can mention the diversity of bacterial flora, infants' feeding factors and hypovitaminosis $\mathrm{D} .{ }^{14}$

The most frequent symptom at baseline was bloody stools $(41.4 \%) ; 58.6 \%$ of the patients developed non-IgE-mediated symptoms, as informed in other reports. ${ }^{9}$

A limitation of our study was its retrospective design, although the diagnosis process was performed by the same team of experts, and having an electronic record allowed us to minimize under-recording. Also, this population had access to health care through a private health insurance, so our sample was not representative of the total Argentine population.

Despite the limitations mentioned, this study contributes new and valuable information which should be supplemented by future investigations.

\section{CONCLUSION}

CMPA prevalence was $1.2 \%$ in 2014 , with an increase of $0.4 \%$ to $1.2 \%$ observed along the period studied.

\section{Acknowledgments}

We would like to thank Carlos Lifschitz, M.D., for his collaboration and experienced contribution.

\section{REFERENCES}

1. Luyt D, Ball H, Makwana N, et al. BSACI guideline for the diagnosis and management of cow's milk allergy. Clin Exp Allergy 2014;44(5):642-72.

2. Fiocchi A, Brozek J, Schünemann H, et al. World Allergy Organization (WAO) Diagnosis and Rationale for Action against Cow's MilkAllergy (DRACMA) Guidelines. World Allergy Organ J 2010;3(4):57-161.

3. Boyce JA, Assa'ad A, Burks S, et al. Guidelines for diagnosis and management of food allergy in the United States: report of the NIAID-sponsored expert panel. J Allergy Clin Immunol 2010;126(6 0):S1-58.

4. Henriksen C,Eggesbø M,Halvorsen R, et al. Nutrient intake among two-year-old children on cows' milk-restricted diets. Acta Paediatr 2000;89(3):272-8.

5. Aceval ML, Muñoz-Furlong A, Sampson HA. Abordaje de la AlergiaAlimentaria. In: Metcalfe D, Sampson H, Simon $\mathrm{R}$, et al, edits. Alergias Alimentarias. $5^{\text {th }}$ ed. Barcelona: Elsevier; 2016. Pgs.446-59.

6. Bozzola C, Ivancevich JC, Ardusso L, et al. Encuestasobrepercepción de salud, conocimiento de las defensasnaturales y prevalencia de enfermedadesalérgicas y patologíasasociadasen Argentina. Módulo Alergia Alimentaria. Study presented as a poster at the AAAeIC's XXXI annual meeting and the SLAAI's XI South American conference; August 16-18, 2007, Buenos Aires. 
7. Eggesbø M, Botten G, Halvorsen R, et al. The prevalence of CMA/CMPI in young children: the validity of parentally perceived reactions in a population-based study. Allergy 2001;56(5):393-402.

8. Venter C, Pereira B, Voigt K, etal. Prevalence and cumulative incidence of food hypersensitivity in the first 3 years of life. Allergy 2008;63(3):354-9.

9. Rancé F, Grandmottet X, Grandjean H. Prevalence and main characteristics of schoolchildren diagnosed with food allergies in France. Clin Exp Allergy 2005;35(2):167-72.

10. Venter C, Arshah SH. Epidemiology of food allergy. Pediatr Clin North Am 2011;58(2):327-49.

11. Nwaru BI, Hickstein L, PanesarSS, et al. The epidemiology of food allergy in Europe: a systematic review and metaanalysis. Allergy 2014;69(1):62-75.

12. Keet CA, Savage JH, Seopaul S, et al. Temporal trends and racial/ethnic disparity in self-reported pediatric food allergy in United States. Ann Allergy Asthma Immunol 2014;112(3):222-9.e3.

13. Allen KJ, Koplin JJ. The epidemiology of IgE-mediated food allergy and anaphylaxis. Immunol Allergy Clin North Am 2012;32(1):35-50.

14. Allen KJ, Koplin JJ. Teorías acerca de la prevalencia creciente de alergias alimentarias. En Metcalfe DD, Sampson HA, Simon RA, et al., edits. Alergias Alimentarias, $5^{\text {th }}$ ed. Barcelona: Elsevier; 2016.Pgs.121-31. 